\title{
The Effect of Cryptocurrency on Investment Portfolio Effectiveness
}

\author{
Yanuar Andrianto, Yoda Diputra \\ Management Department, PPM School of Management, Jakarta, Indonesia \\ Email address: \\ Andrianto77@gmail.com (Y. Andrianto), Yoda.diputra@gmail.com (Y. Diputra)
}

\section{To cite this article:}

Yanuar Andrianto, Yoda Diputra. The Effect of Cryptocurrency on Investment Portfolio Effectiveness. Journal of Finance and Accounting. Vol. 5, No. 6, 2017, pp. 229-238. doi: 10.11648/j.jfa.20170506.14

Received: September 30, 2017; Accepted: December 29, 2017; Published: March 9, 2018

\begin{abstract}
The emergence of financial technology in the last 10 years has created a new type of asset that is Cryptocurrency. Cryptocurreny offers a small transaction fee without involving a third party in its transaction and the ability to make its users anonymous. It became one of its main selling points and was quickly accepted widely in the financial world. Cryptocurrency price movements become volatile. For examples, Bitcoin issued in 2009, the value is not more than USD 10, but in early June 2017, Bitcoin is worth about USD 3000 (Bloomberg, July $5^{\text {th }}, 2017$ ). Many investors are interested to invest in Cryptocurrency, especially investors with high risk tolerance. This study aims to find the effects of Cryptocurrency on well-formed portfolios. The assets we use are Foreign Currency, Commodity, Stock, and ETF. The Cryptocurrency we will use is Bitcoin, Ripple and Litecoin. Using the Modern Portfolio Theory approach, we can create an investment portfolio. The results show that the portfolio with Cryptocurrency indeed increases the effectiveness of the portfolio in two ways. The first is to minimize the standard deviation and the second is to create more allocation options for investors to choose from. The optimum allocation of Cryptocurrency is from $5 \%$ to $20 \%$ depending on the risk tolerance of the investor.
\end{abstract}

Keywords: Cryptocurrentcy, Bitcoin, Ripple, Litecoin, Investment Portfolio, Markowitz

\section{Introduction}

Cryptocurrency or virtual currency is a growing payment system in recent years. Cryptocurrency depends on a digital bookkeeping system called Blockchain. Until now there are several kinds of alternative virtual currencies such as Bitcoin, Litecoin, Ripple, Etherium, and so forth, totaling more than 500 types. Bitcoin became the most widely used digital currency with the largest market capitalization among other digital currencies (Yermack, 2013). This study is limited to three types of Cryptocurrency with the largest trading volume, namely Bitcoin (BTC), Ripple (XRP), and Litecoin (LTC).

Bitcoin was developed by Satoshi Nakamoto in 2009. Bitcoin is recognized as the first Cryptocurrency pioneer focusing on decentralization, meaning that controls on these currencies are in the user itself without any regulatory rules in the transaction. Loss of third parties in transactions, making the cost can be suppressed even disappear completely. This is the main reason for the growing Cryptocurrency. The use of Bitcoin has been done by several well-known companies. The company has already begun to receive payments through
Bitcoin, such as Dell, Microsoft, Valve, Tesla, Amazon, PayPal, and Subway (Bloomberg, 2016).

The risks that arise from Bitcoin is that the movement of Bitcoin values is still very volatile. At the beginning of January 2017, the value of 1 Bitcoin is equivalent to 1000 USD and by June 2017 it has reached 3000 USD. Not only Bitcoin, other Cryptocurrency such as Litecoin, Etherium or Ripple also experienced a very significant exchange rate upheaval. Litecoin that ranges from 6.4 USD per 1 Litecoin in 2013 to around 4.6 USD in 2016. While Ripple which initially 0.035 USD in 2013 decreased to 0.008 USD in December 2016 (Bloomberg, 2017).

Cryptocurrency has a different nature from the conventional currency. Conventional currencies such as dollars and euro are highly dependent on the state and global economic conditions, such as inflation, trade, crises, politics, and so on, so they can be calculated more precisely. However the price and fluctuations of Cryptocurrency are more difficult to determine. Demand and supply is an important factor in the formation of the price of Cryptocurrency, in addition to paying attention to the rumors that contribute to the movement of Cryptocurrency 
prices. The study of Ciaian, Rajcaniova and Kancs (2014), the price of Bitcoin is determined by three things, namely (1) the interaction between demand and supply, (2) attractiveness to investors, and (3) macroeconomic conditions and financial developments.

These unpredictable price changes make it difficult for investors to take the right position in trading and investing to get the most benefit. There are substantial risks in Cryptocurrency investment, including exchange rate risk, operational, and security. There needs to be a more in-depth study to be able to determine the most appropriate strategy for investors.

Investors still rely heavily on speculation and rumors circulating in managing Cryptocurrency assets. Researchers tried to use a portfolio selection model developed by Markowitz (1952). This model serves to maximize return and minimize risk, by diversifying into some form of Cryptocurrency assets. This model is often used to determine the allocation of assets in the portfolio, but very rarely involve Cryptocurrency in the diversification. This research is expected to decrease the bias or level of speculation from investor so as to form optimal portfolio.

Wu and Pandey (2014) examine the effect of Bitcoin in the investment portfolio, and conclude that there is an increase in portfolio effectiveness when Bitcoin is allocated. This study tried to use more assets, not just Bitcoin. The researcher broadens the view of Cryptocurrency instruments by trying to provide a portfolio diversification strategy that is appropriate by using some portfolio formation models. This study has two purposes. First, it aims to establish optimal risky portfolio based on Modern Portfolio Theory. Second, to see the effect of Cryptocurrency on conventional asset investment portfolio

\section{Literature Review}

Modern Portfolio Theory (MPT) states how an investor with a high risk aversion value can develop an investment portfolio to maximize return based on existing market risk. Markowitz (Portfolio Selection, 1952) revealed that by establishing Efficient Frontier, can know the level of return from each level of risk.

This MPT relies on several kinds of investment instruments which are then compiled by previously measuring the level of correlation, covariance, standard deviation, and the rate of return using historical statistical methods. In general, MPT combines several portfolios with a high risk of low correlation, and ultimately is expected to decrease the total level of total risk.

The next step is to do a return and risk analysis of the securities within a certain timeframe. It is important for investors to valuate the intrinsic value of securities selected through the Capital Asset Pricing Model (CAPM). Beta is measured to see the relationship between market return and investment by considering the risk free rate.

Measurement of selected asset allocation based on sharpe ratio value of each allocation. Sharpe ratio proposed by William Sharpe (1994) which describes the level of return earned from each measure of risk in the investment. The higher the sharpe ratio the better the return, but not necessarily the optimal portfolio diversification. From the various allocations that describe the return and sharpe ratio, then formed Efficient Frontier diagram illustrating the $\mathrm{X}$ axis as a risk and $\mathrm{Y}$ axis as a return. The point in this hyperbola diagram is then described as the best option for investors to invest according to their own utility level. This method will ultimately minimize the risk of deviation than if only selecting a particular asset. Investors should remain cautious because of the risks that exist in Bitcoin and only allocate small portions into it (Wu and Pandey, 2014).

Gandals and Halaburda (2016) try to see the existing competition of the many types of Cryptocurrency that are now circulating. His findings state that Bitcoin was the winner in the virtual currency competition within the timeframe of the study. Researchers also refer to previous research to develop the analysis. The study of Law and Mills (2014) analyzed the behavior of Bitcoin investors. Their hypothesis is that Bitcoin investors will use the Technical Analysis function in making decisions between buy/sell. The results show that there are two possibilities, ie investors more often use counterstrategy, or less supportive data. Deficiencies in counterstrategy, ie optimal buying and selling points can not be determined until the time of the incident.

Kim., et al (2016) analyzed the relationship between activity in the forum with the number of transactions from 3 Cryptocurrency such as Bitcoin, Ethereum and Ripple. The results show comments and replies in forums and online communities are influential in the number of virtual currency transactions, and affect the opinions of investors. Bitcoin price fluctuations are generally affected by positive comments, while Ethereum and Ripple are more affected by negative comments. In contrast to price fluctuations, fluctuations in the number of transactions are more affected by the number of replies than the number of comments made.

One of Bitcoin's criteria as a new investment asset is Correlation of returns: Price Independence. In terms of optimal portfolio formation, correlation becomes an important thing. Burniske and White (2016) calculated the correlation between Bitcoin with S \& P 500, Gold, US Bonds, US Real Estate, Oil, and Emerging Market Currencies. Bitcoin will grow and become a differentiator among other assets and can potentially transform the financial world. Baur, Hong and Lee (2016) analyzed the return and correlation of Bitcoin compared to 16 other assets including stocks, bonds, energy, currency, and precious metals. The result is that Bitcoin has the highest return and standard deviation compared to other assets of $7.6 \%$. Associated with the correlation, similar to many previous studies, they found no significant correlation between Bitcoin and other assets.

Eisl, Gasser and Weinmayer (2015) analyzed the effect of Bitcoin in the portfolio. Assets used include stocks, fixed income, money market, property, and commodities. From the historical data determined, the highest asset allocation of Bitcoin is $7.69 \%$ is in the portfolio where the load of each asset is the same. This portfolio generates a monthly average 
return of $1.93 \%$. The result concludes that the allocation of Bitcoin in the portfolio brings good influence in the investment portfolio.

\section{Research Methods}

The research focuses on Cryptocurrency and its allocation in the portfolio to produce an optimal portfolio. The object of this study was chosen because of the use of Cryptocurrency increasingly experienced popularity since its first appearance in 2009. Its different characteristics from other conventional assets has also attracted many investors to start investing in Cryptocurrency. This phenomenon takes place globally supported by many major countries such as China, Japan, and also the United States.

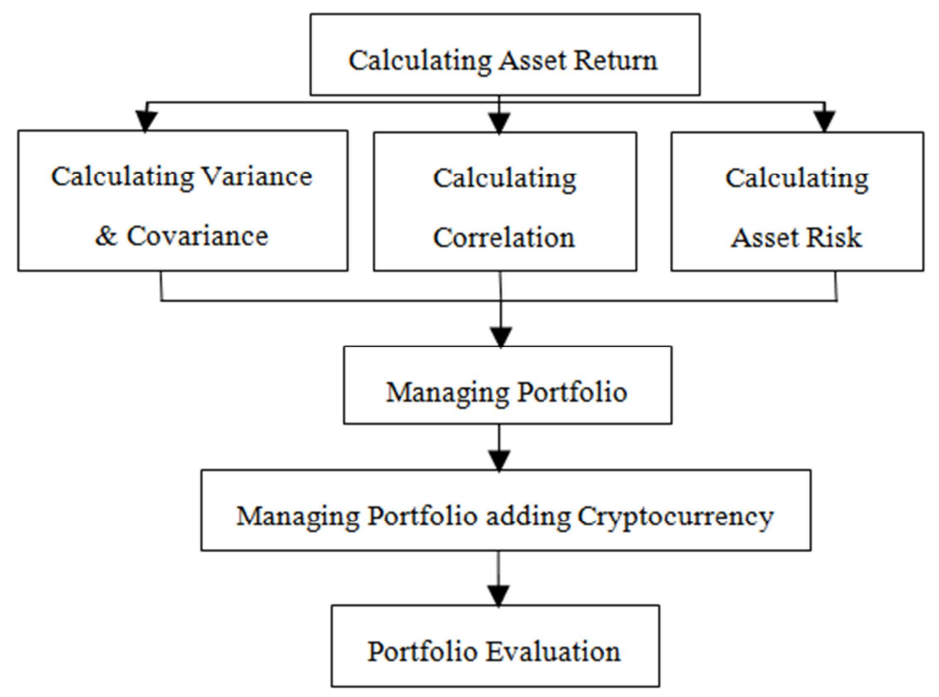

Figure 1. Framework Analysis.

The first step of this research is to collect historical data of assets to be used as analytical instruments. The data is taken from www.investing.com, https://finance.yahoo.com and www.cryptocompare.com. Period of data taken is from December 2013 to December 2016. The data is processed using the help of Microsoft Excel software and some formulas that are inside.

Foreign exchange (FOREX) and commodities consists of 11 asset types. Foreign exchange is chosen because it is the type of asset whose characteristics are most closely related to Cryptocurrency, ie as a means of exchange of payment. Commodities themselves are chosen because it is the investment option that is considered the safest, especially gold. Bitcoin itself is often compared to gold because it is resistant to economic shocks, as Baur, et al (2016) puts it. These assets are USD/RUB - US Dollar Russian Ruble, USD/DKK - US Dollar Danish Krone, USD/CNY - US Dollar Chinese Yuan, USD/HKD - US Dollar Hong Kong Dollar, USD/CAD - US Dollar Canadian Dollar, USD/SGD - US Dollar Singapore Dollar, USD/CHF - US Dollar Swiss FranceEUR/GBP - Euro British Pound, Metal, Gold, and Silver.

Portfolio of Stocks are the preferred asset used by investors in portfolio formation. The data used six stocks in the formation of a portfolio, namely The Kraft Heinz Company (KHC), Wells Fargo \& Company (WFC), The Coca-Cola Company (KO), International Business Machines Corporation (IBM), American Express Company (AXP), and Phillips 66 (PSX). These shares are some of the shares owned by Warren Buffett. This research assume are these shares represent stock assets in stock portfolios.

ETF are a collection of assets based on indexes. Researchers chose five ETF that are popular among investors such as Vanguard Total Stock Market ETF (VTI), Vanguard Total Bond Market ETF (BND), Vanguard FTSE All-World ex-US ETF (VEU), PowerShares DB US Dollar Bullish ETF (UUP), and SPDR S\&P Metals and Mining ETF (XME).

The next step is to find annual return and standard deviation. Some functions used include stdev (calculate standard deviation), correl (calculate correlation), covar (counting covariance), and average (calculate mean). Another function that is then used is a solver, which is very useful for providing solutions in linear programming and able to provide the constraints needed to form asset allocations. Solver will allocate assets in accordance with the objectives we have set, so that an optimal portfolio can be established.

This research try managed four investment portfolios. The first portfolio consists of both Foreign Currency and Commodity, the second is a portfolio comprising a pool of Stock assets, and the third portfolio is a portfolio of ETFs. The fourth portfolio is a combined portfolio of the best performing assets of each portfolio. The risk-free level that researchers use in each portfolio calculation is $0.5 \%$ taken based on the 3 month return of US Treasury Bill.

\section{Results}

\subsection{Portfolio Performance of FOREX and Commodities}

This portfolio consists of 11 asset types of foreign exchange 
and commodities. Foreign exchange is chosen because it is the type of asset whose characteristics are closest to Cryptocurrency, ie as a means of exchange of payment. Commodities themselves are chosen because it is the investment option that is considered the safest, especially gold. Bitcoin itself is often compared to gold because it is resistant to economic shock (Baur, 2016). The first steps, the asset is analyzed for returns and risks in the period December 2013 through December 2016. Return and risk analysis will be the basis of portfolio formation. The following table illustrates the performance of each asset in this portfolio

The next step, the researchers formed a portfolio with optimal asset allocation. The constraint that the researcher uses is total asset allocation equal to $100 \%$, asset allocation greater than or equal to 0 , and return from portfolio equal to return from target that the researcher specify. In addition, the researchers also used the objective of maximizing the sharpe ratio. Sharpe ratio is a measure used to assess the rate of return generated from each risk. The results are as follows:

Table 1. Asset Allocation Portfolio of FOREX and Commodities.

\begin{tabular}{|c|c|c|c|c|c|c|}
\hline Allocation & 1 & 2 & 3 & 4 & 5 & 6 \\
\hline Return & $4.45 \%$ & $5.00 \%$ & $6.03 \%$ & $10.00 \%$ & $15.00 \%$ & $20.00 \%$ \\
\hline STD.DEV & $4.09 \%$ & $2.54 \%$ & $3.06 \%$ & $6.14 \%$ & $10.80 \%$ & $17.12 \%$ \\
\hline Sharpe & $108.8 \%$ & $196.5 \%$ & $197.1 \%$ & $162.8 \%$ & $138.9 \%$ & $116.84 \%$ \\
\hline USD/RUB & $9.09 \%$ & $5.31 \%$ & $7.2 \%$ & $23.3 \%$ & $44.8 \%$ & $81.55 \%$ \\
\hline USD/DKK & $9.09 \%$ & $17.6 \%$ & $21.3 \%$ & $35.13 \%$ & $55.21 \%$ & $18.45 \%$ \\
\hline $\mathrm{USD} / \mathrm{CNY}$ & $9.09 \%$ & $51.2 \%$ & $57.8 \%$ & $38.4 \%$ & $0.00 \%$ & $0.00 \%$ \\
\hline USD/HKD & $9.09 \%$ & $12.7 \%$ & $0.00 \%$ & $0.00 \%$ & $0.00 \%$ & $0.00 \%$ \\
\hline USD/SGD & $9.09 \%$ & $0.00 \%$ & $0.00 \%$ & $0.00 \%$ & $0.00 \%$ & $0.00 \%$ \\
\hline USD/CHF & $9.09 \%$ & $0.5 \%$ & $0.05 \%$ & $0.44 \%$ & $0.00 \%$ & $0.00 \%$ \\
\hline EUR/GBP & $9.09 \%$ & $8.6 \%$ & $9.4 \%$ & $0.00 \%$ & $0.00 \%$ & $0.00 \%$ \\
\hline Metal & $9.09 \%$ & $0.04 \%$ & $0.00 \%$ & $0.04 \%$ & $0.00 \%$ & $0.00 \%$ \\
\hline Gold & $9.09 \%$ & $1.7 \%$ & $1.3 \%$ & $0.84 \%$ & $0.00 \%$ & $0.00 \%$ \\
\hline Silver & $9.09 \%$ & $2.4 \%$ & $2.9 \%$ & $1.85 \%$ & $0.00 \%$ & $0.00 \%$ \\
\hline
\end{tabular}

The test result shows that the allocation of assets proportionally yields only $4.45 \%$ return and risk of $4.09 \%$. Sharpe ratio is highest in allocation 3 of $197.11 \%$ with a return rate of $6.03 \%$ and a risk of $3.06 \%$. At allocation 6 , the researcher allocates to two assets ie USD / RUB and USD / DKK. The researcher did not conduct a simulation of continued asset allocation by fully encoding on USD / RUB. Researchers argue that it is incompatible with Markowitz's theory that promotes diversification as an effort to minimize risk.

Portfolio Performance of FOREX and Commodities Adding Cryptocurrentcy

The next step is to include Cryptocurrency assets into the asset portfolio to see the effect in portfolio performance. Here is the return and standard deviation of Bitcoin (BTC), Ripple (XRP) and Litecoin (LTC):
Table 2. Retun \& Standard Deviation Cryptocurrency.

\begin{tabular}{lll}
\hline & Return & Standard Deviation \\
\hline BTC/USD & $35.53 \%$ & $72.43 \%$ \\
XRP/USD & $-2.80 \%$ & $106.11 \%$ \\
LTC/USD & $31.86 \%$ & $94.24 \%$ \\
\hline
\end{tabular}

Bitcoin calculation results show better performance than Ripple and Litecoin with a return rate of $35.53 \%$ and a standard deviation of $72.43 \%$. Bitcoin and Litecoin return rates are also seen to outperform the returns of forex and commodity assets in the previous portfolio. But in general these three assets are seen to have a very high risk level when compared with other conventional assets.

After the calculation of the covariance can be searched the value of the variant needed to form an optimal asset allocation. Here are the results of the foreign exchange and commodity portfolio by including Cryptocurrency assets.

Table 3. Asset allocation of Cryptocurrency in Forex \& Commodity Portfolio.

\begin{tabular}{|c|c|c|c|c|c|c|c|c|c|}
\hline Allocation & 1 & 2 & 3 & 4 & 5 & 6 & 7 & 8 & 9 \\
\hline Return & $5.00 \%$ & $6.39 \%$ & $8.11 \%$ & $10.00 \%$ & $15.00 \%$ & $20.00 \%$ & $25.00 \%$ & $30.00 \%$ & $35.00 \%$ \\
\hline STD.DEV & $2.43 \%$ & $3.06 \%$ & $13.29 \%$ & $5.55 \%$ & $9.70 \%$ & $14.70 \%$ & $21.16 \%$ & $41.98 \%$ & $69.22 \%$ \\
\hline Sharpe & $185 \%$ & $192.5 \%$ & $57.24 \%$ & $171.2 \%$ & $149.5 \%$ & $132.7 \%$ & $115.8 \%$ & $70.27 \%$ & $49.84 \%$ \\
\hline USD/RUB & $5.2 \%$ & $7.18 \%$ & $7.14 \%$ & $19.3 \%$ & $36.51 \%$ & $61.31 \%$ & $80.88 \%$ & $42.48 \%$ & $4.08 \%$ \\
\hline USD/DKK & $14.9 \%$ & $19.21 \%$ & $7.14 \%$ & $31.12 \%$ & $49.84 \%$ & $28.35 \%$ & $0.00 \%$ & $0.00 \%$ & $0.00 \%$ \\
\hline $\mathrm{USD} / \mathrm{CNY}$ & $49.4 \%$ & $55.40 \%$ & $7.14 \%$ & $40.6 \%$ & $6.55 \%$ & $0.00 \%$ & $0.00 \%$ & $0.00 \%$ & $0.00 \%$ \\
\hline USD/HKD & $20.5 \%$ & $0.00 \%$ & $7.14 \%$ & $0.00 \%$ & $0.00 \%$ & $0.00 \%$ & $0.00 \%$ & $0.00 \%$ & $0.00 \%$ \\
\hline USD/SGD & $0.00 \%$ & $0.00 \%$ & $7.14 \%$ & $0.00 \%$ & $0.00 \%$ & $0.00 \%$ & $0.00 \%$ & $0.00 \%$ & $0.00 \%$ \\
\hline USD/CHF & $0.5 \%$ & $2.71 \%$ & $7.14 \%$ & $0.44 \%$ & $0.00 \%$ & $0.00 \%$ & $0.00 \%$ & $0.00 \%$ & $0.00 \%$ \\
\hline EUR/GBP & $4.5 \%$ & $9.06 \%$ & $7.14 \%$ & $2.69 \%$ & $0.00 \%$ & $0.00 \%$ & $0.00 \%$ & $0.00 \%$ & $0.00 \%$ \\
\hline Metal & $0.00 \%$ & $0.00 \%$ & $7.14 \%$ & $0.00 \%$ & $0.00 \%$ & $0.00 \%$ & $0.00 \%$ & $0.00 \%$ & $0.00 \%$ \\
\hline Gold & $2.3 \%$ & $2.18 \%$ & $7.14 \%$ & $0.00 \%$ & $0.00 \%$ & $0.00 \%$ & $0.00 \%$ & $0.00 \%$ & $0.00 \%$ \\
\hline Silver & $1.8 \%$ & $2.74 \%$ & $7.14 \%$ & $2.60 \%$ & $1.19 \%$ & $0.00 \%$ & $0.00 \%$ & $0.00 \%$ & $0.00 \%$ \\
\hline
\end{tabular}




\begin{tabular}{|c|c|c|c|c|c|c|c|c|c|}
\hline Allocation & 1 & 2 & 3 & 4 & 5 & 6 & 7 & 8 & 9 \\
\hline BTC/USD & $0.99 \%$ & $1.51 \%$ & $7.14 \%$ & $3.28 \%$ & $5.91 \%$ & $10.34 \%$ & $19.12 \%$ & $57.52 \%$ & $95.92 \%$ \\
\hline XRP/USD & $0.00 \%$ & $0.00 \%$ & $7.14 \%$ & $0.00 \%$ & $0.00 \%$ & $0.00 \%$ & $0.00 \%$ & $0.00 \%$ & $0.00 \%$ \\
\hline LTC/USD & $0.06 \%$ & $0.00 \%$ & $7.14 \%$ & $0.00 \%$ & $0.00 \%$ & $0.00 \%$ & $0.00 \%$ & $0.00 \%$ & $0.00 \%$ \\
\hline
\end{tabular}

Based on the above table can be seen that there is a significant increase in portfolio performance, seen from the return rate can reach $35 \%$. The highest Sharpe Ratios are in allocation 2 with a return rate of $6.39 \%$ and a standard deviation of $3.06 \%$. Allocation 3 illustrates the level of returns in the allocation of assets divided equally. This allocation does not show good performance, because with return $8.11 \%$ this allocation has a standard deviation of $13.29 \%$, higher than Allocation 4 which can generate $10 \%$ return and only has $5.55 \%$ deviation standard.

The calculation result by adding Cryptocurrency assets gives a good effect for portfolio performance. For example, in the initial portfolio, the return rate of $20 \%$ has a standard deviation of $17.12 \%$, but in this portfolio, the return rate of $20 \%$ has a smaller standard deviation of $14.70 \%$, decreasing by $2.42 \%$. In addition, this portfolio provides more options for investors with a high level of risk tolerance.

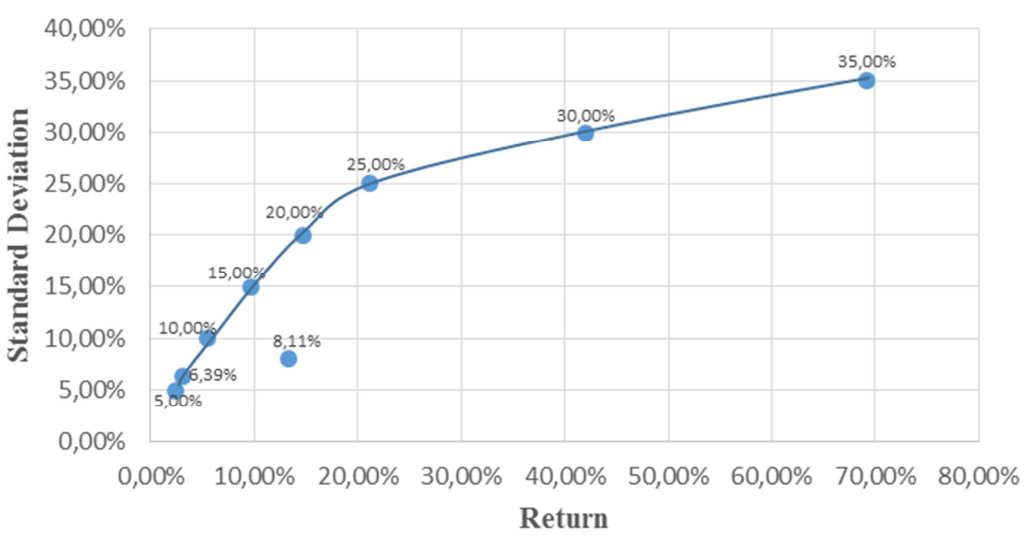

Figure 2. Efficient Frontier: Portfolio of Forex, Commodities \& Cryptocurrency.

Based on the above Efficient Frontier diagram, investors can make a choice of portfolio asset allocation in accordance with the level of risk they have. The results of calculations on the Cryptocurrency portfolio, at any rate of return it is seen that there is always an allocation in Bitcoin of only $0.99 \%$ to the highest $95.92 \%$. However it is not the case with Ripple that does not get any allocation at any rate of return. At least it has been seen that Bitcoin plays a role in portfolio diversification in the form of FOREX and commodity assets.

Bitcoin plays a role in diversifying its portfolio in the form of foreign and commodity assets. Allocates earning a return of $5 \%$ to $20 \%$ can be selected by investors who have a fairly low risk tolerance level, while allocations of $30 \%$ and $35 \%$ are reserved for investors with high risk tolerance. However, this allocation is strongly discouraged due to the uneven diversification of assets. In addition, investors should avoid allocations that generate returns of $8.11 \%$ because they are below the efficient frontier line, which means that there are other asset allocations that can result in greater returns with less risk

\subsection{Portfolio Performance of Stocks}

Stocks are the most common type of assets used by investors in the formation of a portfolio. In this study, there are six stocks used in the formation of a portfolio. The results of these calculations yield some asset allocation options to produce optimal results in the following table:

Table 4. Asset Allocation of Stocks.

\begin{tabular}{|c|c|c|c|c|c|c|}
\hline Allocation & 1 & 2 & 3 & 4 & 5 & 6 \\
\hline Return & $5.00 \%$ & $6.34 \%$ & $10.00 \%$ & $14.15 \%$ & $15.00 \%$ & $20 \%$ \\
\hline STD.DEV & $12.48 \%$ & $13.92 \%$ & $14.30 \%$ & $18.23 \%$ & $19.52 \%$ & $30.97 \%$ \\
\hline Sharpe & $36.05 \%$ & $41.93 \%$ & $66.45 \%$ & $74.88 \%$ & $74.29 \%$ & $62.97 \%$ \\
\hline $\mathrm{KHC}$ & $10.00 \%$ & $16.67 \%$ & $25.57 \%$ & $44.74 \%$ & $52.36 \%$ & $96.94 \%$ \\
\hline WFC & $24.65 \%$ & $16.67 \%$ & $41.40 \%$ & $46.32 \%$ & $40.50 \%$ & $3.06 \%$ \\
\hline $\mathrm{KO}$ & $48.73 \%$ & $16.67 \%$ & $27.45 \%$ & $0.00 \%$ & $0.00 \%$ & $0.00 \%$ \\
\hline IBM & $10.77 \%$ & $16.67 \%$ & $0.00 \%$ & $0.00 \%$ & $0.00 \%$ & $0.00 \%$ \\
\hline PSX & $0.00 \%$ & $16.67 \%$ & $5.58 \%$ & $8.94 \%$ & $7.14 \%$ & $0.00 \%$ \\
\hline
\end{tabular}

Allocation 2 represents uniform proportions yielding only $6.34 \%$ return and a standard deviation of $13.92 \%$. Allocation 4 shows the highest sharpe ratio that yields $14.15 \%$ return and standard deviation of $18.23 \%$. Allocation 6 shows the highest return rate of $20 \%$, but asset allocation is not well diversified, where high deviation standard is $30.97 \%$. Allocations 3 and 4 
are good allocations for investors with moderate risk tolerance levels. This is also supported by the equitable distribution of assets so as to minimize the risks.

Portfolio Performance of Stocks Adding Cryptocurrentcy

In this portfolio, researchers formed 11 asset choices from the $5 \%$ return rate to the greatest $35 \%$. Allocation 3 shows a balanced allocation of all assets, resulting in a return of $11.40 \%$ and a standard deviation of $22.98 \%$. In general, this allocation does not show good performance. Allocation 5 is allocated with the highest sharpe ratio of $88.59 \%$. This allocation provides a return of $17.07 \%$ and a standard deviation of $18.70 \%$.

Table 5. Asset allocation of Cryptocurrency in Stocks Portfolio.

\begin{tabular}{|c|c|c|c|c|c|c|c|c|c|c|c|}
\hline Allocation & 1 & 2 & 3 & 4 & 5 & 6 & 7 & 8 & 9 & 10 & 11 \\
\hline Return & $5.00 \%$ & $10.00 \%$ & $11.40 \%$ & $15.00 \%$ & $17.07 \%$ & $20.00 \%$ & $25.00 \%$ & $30 \%$ & $31 \%$ & $32 \%$ & $35.00 \%$ \\
\hline STD.DEV & $12.45 \%$ & $13.46 \%$ & $22.98 \%$ & $16.74 \%$ & $18.70 \%$ & $22.69 \%$ & $31.51 \%$ & $47.51 \%$ & $51.7 \%$ & $56 \%$ & $69.71 \%$ \\
\hline Sharpe & $36.13 \%$ & $70.56 \%$ & $47.44 \%$ & $86.61 \%$ & $88.59 \%$ & $85.92 \%$ & $77.74 \%$ & $62.09 \%$ & $59 \%$ & $56.2 \%$ & $49.49 \%$ \\
\hline WFC & $27.58 \%$ & $35.66 \%$ & $11.11 \%$ & $42.30 \%$ & $36.81 \%$ & $21.85 \%$ & $0.00 \%$ & $0.00 \%$ & $0.00 \%$ & $0.00 \%$ & $0.00 \%$ \\
\hline $\mathrm{KO}$ & $48.25 \%$ & $32.27 \%$ & $11.11 \%$ & $4.01 \%$ & $0.00 \%$ & $0.00 \%$ & $0.00 \%$ & $0.00 \%$ & $0.00 \%$ & $0.00 \%$ & $0.00 \%$ \\
\hline IBM & $12.34 \%$ & $1.60 \%$ & $11.11 \%$ & $0.00 \%$ & $0.00 \%$ & $0.00 \%$ & $0.00 \%$ & $0.00 \%$ & $0.00 \%$ & $0.00 \%$ & $0.00 \%$ \\
\hline PSX & $0.89 \%$ & $4.85 \%$ & $11.11 \%$ & $10.80 \%$ & $10.94 \%$ & $8.65 \%$ & $0.48 \%$ & $0.00 \%$ & $0.00 \%$ & $0.00 \%$ & $0.00 \%$ \\
\hline BTC/USD & $1.93 \%$ & $5.35 \%$ & $11.11 \%$ & $10.45 \%$ & $13.89 \%$ & $20.11 \%$ & $30.99 \%$ & $63.58 \%$ & $70.2 \%$ & $76.8 \%$ & $96.51 \%$ \\
\hline XRP/USD & $1.67 \%$ & $1.39 \%$ & $11.11 \%$ & $1.08 \%$ & $0.21 \%$ & $0.00 \%$ & $0.00 \%$ & $0.00 \%$ & $0.00 \%$ & $0.00 \%$ & $0.00 \%$ \\
\hline LTC/USD & $0.36 \%$ & $0.00 \%$ & $11.11 \%$ & $0.00 \%$ & $0.00 \%$ & $0.00 \%$ & $0.00 \%$ & $0.00 \%$ & $0.00 \%$ & $0.00 \%$ & $0.00 \%$ \\
\hline
\end{tabular}

If we try to compare asset portfolios with and without involving Cryptocurrency, it can be seen that portfolios involving Cryptocurrency perform better. This can be seen from the return rate of $20 \%$ for example, in the normal portfolio, this return rate has a standard deviation of $30.97 \%$, but in the Cryptocurrency portfolio, the standard deviation rate shows the number $22.69 \%$, down by $8.28 \%$. Also at the $25 \%$ return rate, the Cryptocurrency portfolio shows a standard deviation rate of only $0.54 \%$ higher than the $20 \%$ return rate in the portfolio without Cryptocurrency. Of course this is a good thing for investors in choosing the diversification of their assets.

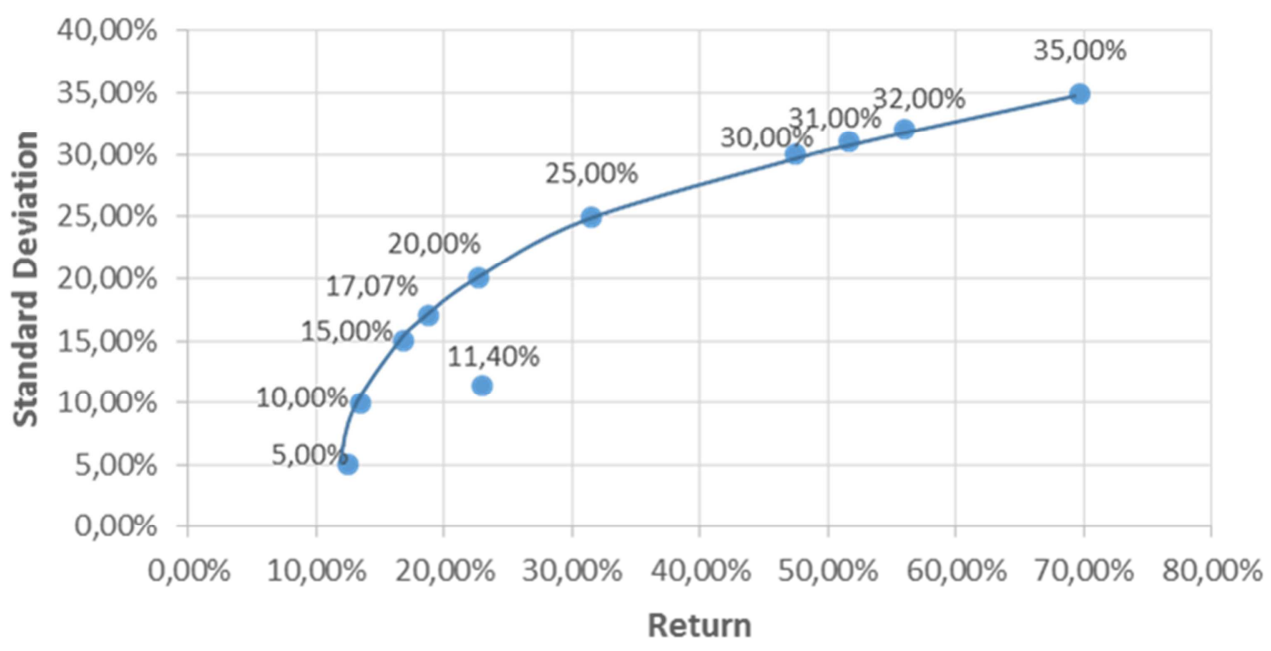

Figure 3. Efficient Frontier: Portfolio of Stocks \& Cryptocurrentcy.

Based on the Efficient Frontier diagram (Figure 3), investors can choose between allocations that generate returns of $5 \%$ to $35 \%$ according to their respective risk tolerance levels to obtain the most optimal results, but not on allocations that generate returns of $11.40 \%$, or Allocation 3. A risk takers can take 9,10 or 11 allocations, while a risk avoider is advised to take a portfolio that generates a $5 \%$ to $20 \%$ return. In this portfolio, as with asset portfolios, Bitcoin always gets allocations, from only $1.93 \%$ to $96.51 \%$. Similarly, Ripple received an allocation of $0.21 \%$ in Allocation 5, up to $1.67 \%$ in Allocation 1. However, it appears that Litecoin is very insignificant, that it only gets $0.36 \%$ allocation in allocation 1 , and this allocation also does not show good performance.

\subsection{Portfolio Performance of Exchange-Traded Fund}

Exchange-Traded Fund (ETF) is an option for investors who prefer their assets to be well diversified without having to set it up on their own. ETFs are a collection of assets based on indexes. There are many kinds of ETFs and each refers to different indexes. ETFs are relatively cheaper because there is no commission cost compared to index funds, or even mutual funds that rely on professional services to manage portfolios, which of course will cost more. There are five ETFs to form this portfolio. The considerations that researchers are using are ETFs are some of the ETFs that are popular among investors. Based on the results of the solver, the following table shows the allocation of 
assets with a minimalist objective variants:

Table 6. Asset Allocation of ETF.

\begin{tabular}{lllllll}
\hline Allocation & $\mathbf{1}$ & $\mathbf{2}$ & $\mathbf{3}$ & $\mathbf{4}$ & $\mathbf{5}$ & $\mathbf{6}$ \\
\hline Return & $3.00 \%$ & $4.00 \%$ & $4.68 \%$ & $5.00 \%$ & $6.00 \%$ & $7.00 \%$ \\
STD.DEV & $2.91 \%$ & $3.68 \%$ & $4.34 \%$ & $4.68 \%$ & $5.81 \%$ & $7.00 \%$ \\
Sharpe & $85.88 \%$ & $95.19 \%$ & $96.20 \%$ & $96.06 \%$ & $94.65 \%$ & $92.88 \%$ \\
VTI & $10.40 \%$ & $14.49 \%$ & $16.80 \%$ & $17.88 \%$ & $21.28 \%$ & $24.67 \%$ \\
BND & $58.66 \%$ & $44.74 \%$ & $34.85 \%$ & $30.15 \%$ & $15.56 \%$ & $0.97 \%$ \\
VEU & $0.00 \%$ & $0.00 \%$ & $0.00 \%$ & $0.00 \%$ & $0.00 \%$ & $0.00 \%$ \\
UUP & $30.50 \%$ & $40.76 \%$ & $48.35 \%$ & $51.97 \%$ & $63.17 \%$ & $74.37 \%$ \\
XME & $0.43 \%$ & $0.00 \%$ & $0.00 \%$ & $0.00 \%$ & $0.00 \%$ & $0.00 \%$ \\
\hline
\end{tabular}

From this table shows that the greatest allocation tendency is in UUP assets. All allocations appear to have a return rate and a standard deviation that is only slightly adrift. For example Allocation 6, has the same return and standard deviation of $7 \%$. This allocation also shows the allocation with the highest sharpe ratio value. Other allocations also illustrate differences that do not differ greatly, only in the range below $0.5 \%$. When viewed from the diversification of asset allocations, VEU and XME rarely even never get allocation. It is reasonable to see the asset's performance during this study period.

Portfolio Performance of Exchange-Traded Fund and Cryptocurrenctcy

Furthermore, by using solver help the researchers form an optimal portfolio. This is to see how Cryptocurrency can affect the formation of a pre-established ETC portfolio allocation. The result is nine asset allocations that show a return rate of $5 \%$ to $35 \%$. Diversification in general is not very equitable, ie more allocated to UUP assets, same as previous portfolio. Allocation 2 shows the division of assets resulting in the highest sharpe ratio of $110 \%$, but the return rate is low at only $5.76 \%$ which may be less attractive to some investors. Allocation 3 shows an equitable distribution of assets. It appears that this allocation does not show good performance due to the high standard deviation rate of $23.93 \%$ with retun rate of only $9.24 \%$. If we compare with the previous portfolio, we can see the return rate on this portfolio can reach $35 \%$, but researchers strongly discourage investors to choose this allocation due to lack of diversification and high standard deviation. Allocation 4 according to the researchers is the most optimal allocation because it produces a relatively high sharpe ratio followed by a good return also of $10 \%$.

Table 7. Asset Allocation of Cryptocurrency in ETF.

\begin{tabular}{|c|c|c|c|c|c|c|c|c|c|}
\hline & 1 & 2 & 3 & 4 & 5 & 6 & 7 & 8 & 9 \\
\hline Return & $5.00 \%$ & $5.76 \%$ & $9.24 \%$ & $10.00 \%$ & $15.00 \%$ & $20.00 \%$ & $25.00 \%$ & $30.00 \%$ & $35.00 \%$ \\
\hline STD.DEV & $4.12 \%$ & $4.78 \%$ & $23.93 \%$ & $9.52 \%$ & $20.43 \%$ & $32.68 \%$ & $45.21 \%$ & $57.95 \%$ & $70.83 \%$ \\
\hline Sharpe & $109 \%$ & $110 \%$ & $37 \%$ & $100 \%$ & $71 \%$ & $60 \%$ & $54 \%$ & $51 \%$ & $49 \%$ \\
\hline VTI & $14.66 \%$ & $16.43 \%$ & $12.50 \%$ & $24.88 \%$ & $30.92 \%$ & $36.95 \%$ & $37.56 \%$ & $19.73 \%$ & $1.89 \%$ \\
\hline BND & $40.84 \%$ & $32.42 \%$ & $12.50 \%$ & $0.00 \%$ & $0.00 \%$ & $0.00 \%$ & $0.00 \%$ & $0.00 \%$ & $0.00 \%$ \\
\hline VEU & $0.00 \%$ & $0.00 \%$ & $12.50 \%$ & $0.00 \%$ & $0.00 \%$ & $0.00 \%$ & $0.00 \%$ & $0.00 \%$ & $0.00 \%$ \\
\hline UUP & $41.92 \%$ & $47.94 \%$ & $12.50 \%$ & $64.86 \%$ & $41.47 \%$ & $18.08 \%$ & $0.00 \%$ & $0.00 \%$ & $0.00 \%$ \\
\hline BTC & $2.58 \%$ & $3.20 \%$ & $12.50 \%$ & $10.26 \%$ & $27.61 \%$ & $44.97 \%$ & $62.44 \%$ & $80.27 \%$ & $98.11 \%$ \\
\hline XRP & $0.00 \%$ & $0.00 \%$ & $12.50 \%$ & $0.00 \%$ & $0.00 \%$ & $0.00 \%$ & $0.00 \%$ & $0.00 \%$ & $0.00 \%$ \\
\hline LTC & $0.00 \%$ & $0.00 \%$ & $12.50 \%$ & $0.00 \%$ & $0.00 \%$ & $0.00 \%$ & $0.00 \%$ & $0.00 \%$ & $0.00 \%$ \\
\hline
\end{tabular}

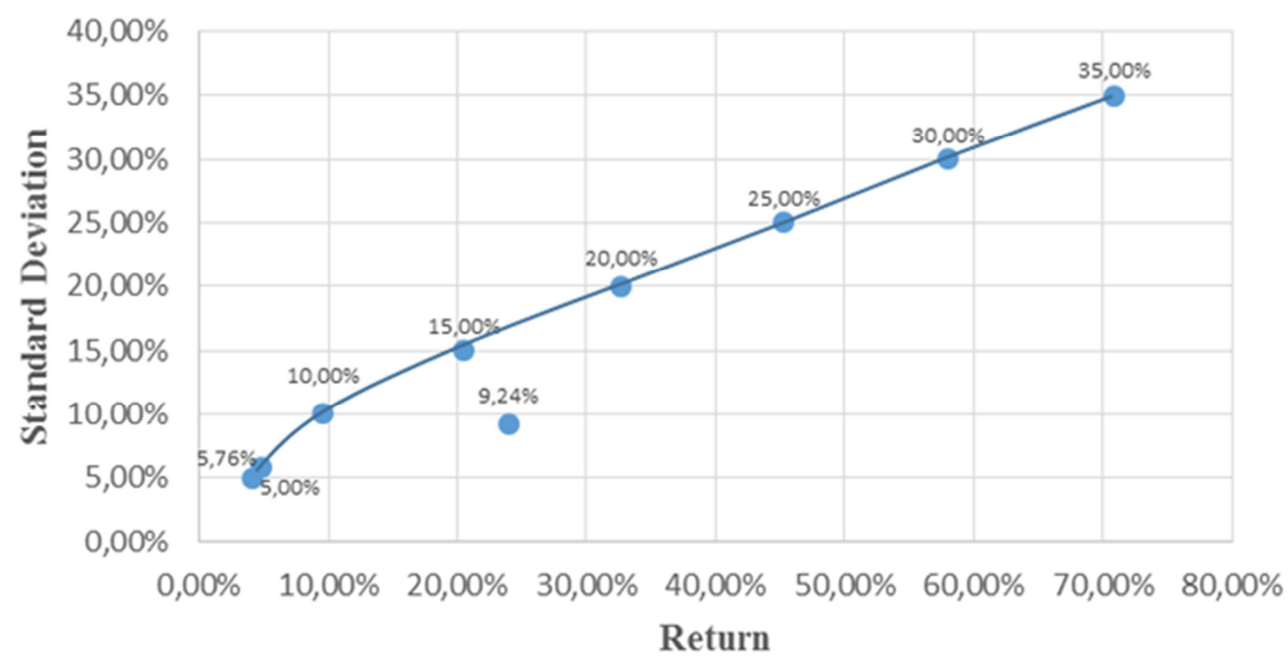

Figure 4. Efficient Frontier: Portfolio of ETFs \& Cryptocurrentcy. 
Results of Efficient Frontier diagram illustrates the level of allocation that should be chosen by the investor. A good allocation is seen in Allocations 4 and 5. Allocation 4 looks like a continuation of the previous portfolio, i.e a return rate similar to the standard deviation rate generated. Allocations that generate $5 \%$ to $15 \%$ retun are suitable allocations for investors with low tolerance levels because standard deviation rates are sufficient. At the rate of return above, can be a consideration for investors who have high risk tolerance. In general, Bitcoin appears to play a role in this portfolio with allocations ranging from $2.58 \%$ to $98.11 \%$. Unlike Bitcoin, Ripple and Litecoin do not get any allocation from the solver at any rate of return.

\subsection{Portfolio Performance of Mixed Assets}

In this portfolio, using some assets from the previous portfolio that have the best performance, so this portfolio will consist of assets forex, stock, ETF, and also Cryptocurrency. But just as before, the first step will be established 2 portfolio first without and with the Cryptocurrency. The following assets are included in this portfolio: USD / RUB - US Dollar Russian Ruble, USD / DKK - US Dollar Danish Krone, The Kraft Heinz Company (KHC), Wells Fargo \& Company (WFC), Vanguard Total Stock Market ETF (VTI), and Power Shares DB US Dollar Bullish ETF (UUP).

We divide our portfolio into five levels of return and standard deviation. Allocation 2 shows the equitable distribution of assets. This allocation yields a return of $12.54 \%$ with a standard deviation of $8.64 \%$. By risk, this allocation does not show good performance, because with lower standard deviation levels, Allocations 3 and 4 can result in a higher rate of return. Allocation 3 shows the allocation with the highest sharpe ratio with return of $13.84 \%$ and the standard deviation of $7.76 \%$. In general, all allocation options describe good performance and well diversified as well. This is illustrated by the level of sharpe ratio of all allocations that are above $100 \%$. Sharpe ratios above 1 or $100 \%$ have been considered good in a portfolio (Table 7).

Table 8. Asset Allocation of a Mixed Portfolio.

\begin{tabular}{llllll}
\hline Allocation & $\mathbf{1}$ & $\mathbf{2}$ & $\mathbf{3}$ & $\mathbf{4}$ & $\mathbf{5}$ \\
\hline Return & $10.00 \%$ & $12.54 \%$ & $13.84 \%$ & $15.00 \%$ & $20.00 \%$ \\
STD.DEV & $6.41 \%$ & $8.64 \%$ & $7.76 \%$ & $8.56 \%$ & $13.51 \%$ \\
Sharpe & $148.21 \%$ & $139.27 \%$ & $171.82 \%$ & $169.49 \%$ & $144.33 \%$ \\
USD/RUB & $16.07 \%$ & $16.67 \%$ & $31.73 \%$ & $37.62 \%$ & $60.76 \%$ \\
USD/DKK & $0.00 \%$ & $16.67 \%$ & $29.72 \%$ & $22.86 \%$ & $0.00 \%$ \\
KHC & $3.11 \%$ & $16.67 \%$ & $9.00 \%$ & $11.93 \%$ & $24.96 \%$ \\
WFC & $0.00 \%$ & $16.67 \%$ & $0.00 \%$ & $0.00 \%$ & $11.31 \%$ \\
VTI & $26.87 \%$ & $16.67 \%$ & $29.55 \%$ & $27.59 \%$ & $2.97 \%$ \\
UUP & $53.95 \%$ & $16.67 \%$ & $0.00 \%$ & $0.00 \%$ & $0.00 \%$ \\
\hline
\end{tabular}

Portfolio Performance of Mix Portfolio Fund and Cryptocurrentcy

Portfolio results compared to the previous portfolio, there is a good performance improvement. For example, at a $15 \%$ retun rate, the deviation standard is $7.98 \%$ or decreased by $0.58 \%$, and at a $20 \%$ return rate, the standard deviation indicates a value of $12.21 \%$ or decreases by $1.30 \%$ from the previous allocation of $13.51 \%$. Differences from the standard deviation side do not show very significant figures, but on the other hand, Cryptocurrency participation provides more options for investors to choose asset allocation rates that generate higher returns.

Table 9. Asset Allocation of a Mixed Portfolio and Cryptocurrentcy.

\begin{tabular}{|c|c|c|c|c|c|c|c|c|}
\hline Allocation & 1 & 2 & 3 & 4 & 5 & 6 & 7 & 8 \\
\hline Return & $10.00 \%$ & $14.6 \%$ & $15.00 \%$ & $15.5 \%$ & $20.00 \%$ & $25.00 \%$ & $30.00 \%$ & $35.00 \%$ \\
\hline Stdev & $6.31 \%$ & $7.73 \%$ & $7.98 \%$ & $21.5 \%$ & $12.21 \%$ & $19.9 \%$ & $41.9 \%$ & $69.2 \%$ \\
\hline Sharpe & $150.5 \%$ & $182 \%$ & $181.75 \%$ & $69.9 \%$ & $159.7 \%$ & $123 \%$ & $70.3 \%$ & $49.8 \%$ \\
\hline USD/RUB & $14.3 \%$ & $30.7 \%$ & $32.46 \%$ & $11.1 \%$ & $52.68 \%$ & $62.54 \%$ & $42.5 \%$ & $4.08 \%$ \\
\hline USD/DKK & $0.00 \%$ & $28.6 \%$ & $26.34 \%$ & $11.1 \%$ & $0.40 \%$ & $0.00 \%$ & $0.00 \%$ & $0.00 \%$ \\
\hline $\mathrm{KHC}$ & $2.31 \%$ & $8.34 \%$ & $9.19 \%$ & $11.1 \%$ & $19.42 \%$ & $15.7 \%$ & $0.00 \%$ & $0.00 \%$ \\
\hline WFC & $0.00 \%$ & $0.00 \%$ & $0.00 \%$ & $11.1 \%$ & $4.19 \%$ & $0.00 \%$ & $0.00 \%$ & $0.00 \%$ \\
\hline UUP & $55.78 \%$ & $0.00 \%$ & $0.00 \%$ & $11.1 \%$ & $0.00 \%$ & $0.00 \%$ & $0.00 \%$ & $0.00 \%$ \\
\hline BTC/USD & $1.41 \%$ & $3.55 \%$ & $3.85 \%$ & $11.1 \%$ & $7.24 \%$ & $21.7 \%$ & $57.5 \%$ & $95.9 \%$ \\
\hline XRP/USD & $0.11 \%$ & $0.00 \%$ & $0.00 \%$ & $11.1 \%$ & $0.00 \%$ & $0.00 \%$ & $0.00 \%$ & $0.00 \%$ \\
\hline LTC/USD & $0.00 \%$ & $0.00 \%$ & $0.00 \%$ & $11.1 \%$ & $0.00 \%$ & $0.00 \%$ & $0.00 \%$ & $0.00 \%$ \\
\hline
\end{tabular}

Based on the Efficient Frontier Portfolio of Mixed and Cryptocurrency diagrams, investors can choose allocations that generate the most secure return rates of $10 \%$, up to $35 \%$ of the highest risk levels. This is because the return of $15.53 \%$ has a higher risk level than return 25\%. The researcher considers Allocation 5 as the best allocation because it has a high average sharpe ratio of $159.71 \%$ and also has diversification or equitable distribution of assets. In this portfolio it is generally seen that there is an allocation of Bitcoin of $1.41 \%$ to $95.92 \%$. But just as with any other portfolio that includes Cryptocurrency, Ripple and Litecoin does not seem to be an option in allocation. Ripple is allocated only $0.11 \%$ in Allocation 1 , whereas Litecoin is not allocated at all, except of course on the same portfolio.

\subsection{Portofolio Evaluations}

The S \& P 500 generated an annual return of $7.77 \%$ with a standard deviation of $12.43 \%$, while the Dow Jones yielded a return of $7.61 \%$ with a standard deviation of $12.54 \%$. From this it can be seen that the portfolio formed using Modern Portfolio Theory can produce better retun performance. Modern Portfolio Theory offers a simpler method than the Black-Litterman model. Some of the limitations that appear 
when using the Black-Litterman model include: 1) Portfolio formation is highly dependent on the index as a benchmark. This is a problem because until now there is no index that represents Cryptocurrency, so difficult to do analysis. 2) The views of analysts or experts in a market, sector or securities are needed to establish equilibrium formation. The need for this expert view becomes an obstacle because Cryptocurrency is a new type of asset that has not many experts on it. Views are also so diverse that it is difficult to determine the best input.

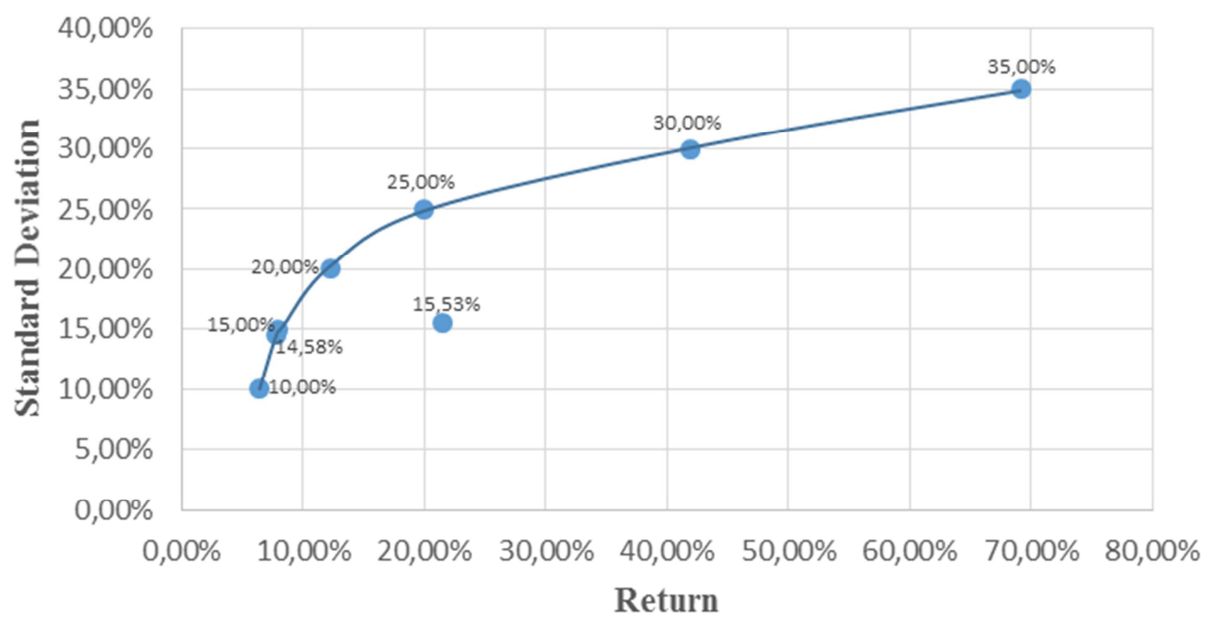

Figure 5. Efficient Frontier: Portfolio of Mixed Assets \& Cryptocurrentcy.

After obtaining the asset composition for optimal portfolio formation, the researcher then tries to see how the asset allocation performance in several periods, ie monthly, semi annual, and annual. The portfolio that researchers use is a mixed portfolio of some of the best performing assets and includes Cryptocurrency. This portfolio researchers use because it shows the best performance among other portfolios. While the allocation of selected assets is the allocation that produces the largest sharpe ratio of $182.05 \%$ and generate return of $14.58 \%$ and standard deviation of $7.73 \%$.

Table 10. Asset Portfolio Allocation with the highest Sharpe Ratio.

\begin{tabular}{llllllll}
\hline USD/RUB & USD/DKK & KHC & WFC & VTI & UUP & BTC/USD & XRP/USD \\
\hline $30.71 \%$ & $28.57 \%$ & $8.34 \%$ & $0.00 \%$ & $28.8 \%$ & $0.0 \%$ & $3.55 \%$ & $0.00 \%$ \\
\hline
\end{tabular}

On average, the return per month in 2014 was $0.56 \%$, by 2015 by $0.20 \%$ and by 2015 by $0.19 \%$. If we calculate again on average from all periods of 2013 to 2016, it is found that the average monthly return is $0.31 \%$.

Similarly, the calculation of the return period of monthly and six monthly, 2014 still shows the best performance, while the year 2016 showed poor performance. This poor performance is due to weakening USD / RUB exchange rate and showing a return $-0.17 \%$, plus asset allocation in a large portfolio of $30.71 \%$. On average, the calculation of the annual period yields a return of $0.29 \%$.

Based on the results of monthly, semi-annual, and annual analysis, using asset allocation based on Modern Portfolio Theory, it can be seen that the return generated is greater if investors invest monthly, ie $0.31 \%$. But the actual return generated is not too much different also when compared with the investment for six months or one year, the difference is only about $0.02 \%$ to $0.05 \%$. This indicates that investors can be more flexible in taking positions, tailored to their level of liquidity and preferences.

The researcher suggests that investors should consider investing monthly, due to the highly volatile characteristics of Cryptocurrency assets, so that if there is a significant price movement, investors can quickly rebalancing or forming new portfolios. An investor can easily get Cryprocurrency without having to spend large capital or through difficult steps.

\section{Conclusion}

Cryptocurrency has a high risk which is indicated by a standard deviation rate that can reach more than $100 \%$. This is consistent with the high rate of return. This increase can be seen from two things, the first is a decrease in the standard deviation rate from the same rate of return, and second is the increase in allocation options to produce higher returns, which may be more attractive to some investors who have high risk tolerance. Cryptocurrency improves the effectiveness of the portfolio. Bitcoin allocation in the portfolio ranges from below $1 \%$ to above $90 \%$. The optimal allocation is at the $5 \%$ to $20 \%$ level to get a good sharpe ratio. This assumption also depends on the performance of other assets, if the worse Bitcoin allocation will be. Looking at monthly, semiannual, and annual historical data, it seems more profitable for investors to invest in monthly periods, although the results obtained are not much greater than in the medium or yearly. Modern Portfolio Theory has proven to be quite effective as a foundation in the establishment of this portfolio. Based on a brief analysis it appears that the formation of a portfolio involving Cryptocurrency has been able to beat the performance of the S \& P 500 and Dow Jones indexes. 


\section{References}

[1] Baur. D. G, Hong. K, Lee. A. D, "Virtual Currencies: Media Of Exchange or Speculative Asset?", June 2016.

[2] Bloomberg.

https://www.bloomberg.com/news/articles/2017-09-18/bitcoin -roars-back-from-chinese-regulation-spurred-swoon. September 2017.

[3] Brander, K, Cryptocurrency - the new global financial crisis?, 2014.

[4] Chris. B and Adam. W, "Bitcoin: Ringing The Bell For New Asset Class", 2016.

[5] Christodoulakis, G. A. "Bayesian Optimal Portfolio Selection: the BlackLitterman Approach.” November 2002.

[6] Ciaian, P, Rajcaniova, M, Kancs, A, "The Economics of BitCoin Price Formation”, 2015.

[7] Delaney, J, Buchholz, M, Warren, J and Parker, J, "Bits and bets information, price volatility, and demand for bitcoin", 2012.

[8] Dewi, D. A and Soekarno, S, "Alternative Investments Evaluation of Bitcoins, Gold and LQ45 Index”, 2014.

[9] Dwyer, Gerald P., The Economics of Bitcoin and Similar Private Digital Currencies, 2014.

[10] Eisl. A, Gasser. S, M, Weinmayer, K. "Caveat Emptor: Does Bitcoin Improve Portfolio Diversification?” June 3, 2015.

[11] Elton. E and Martin. G, Modern Potfolio Theory and Investment Analysis, John Wilet \& Sons. Inc, Canada, 1991.

[12] Gandal, N, and Halaburda, H, "Can We Predict the Winner in a Market with Network Effects? Competition in Cryptocurrency Market", 7 Juli 2016.

[13] Hartono, Jogiyanto. Teori Portofolio dan Analisis Investasi. Edisi Ketujuh. Yogyakarta:BPFE. 2010.

[14] Homeland Security Studies And Analysis Institute, "Risks And Threats Of Cryptocurrencies", December 31, 2014.

[15] Huhtinen, T. P, "Bitcoin as a monetary system: Examining attention and attendance", 2014.

[16] Jones, Charles, P. Investment: Analysis and Management (7th Edition). USA: Wiley \& Son, Inc. 2000.

[17] Kelly, M "Best Practice For Bitcoins Regulatory, Legal And Financial Approaches To Virtual Currencies In A Hesitant, Global Environment", 2014.

[18] Kim YB, Kim JG, Kim W, Im JH, Kim TH, Kang SJ, "Predicting Fluctuations in Cryptocurrency Transactions Based on User Comments and Replies", 2016.

[19] Kristoufek, L, "What are the main drivers of the bitcoin price? evidence from wavelet coherence analysis", 2014.

[20] Kristoufek, L, "Bitcoin meets google trends and wikipedia: Quantifying the relationship between phenomena of the internet era", Nature, 0.1038, 2014.

[21] Lew. A, Mills. W, "Identifying Active Trading Strategies in the Bitcoin Market", 2014.

[22] Markowitz, H. M. "Portfolio Selection." The Journal of Finance, March 1952.

[23] Matsumoto, T, Iwamura, M, Kitamura, Y, "Is bitcoin the only Cryptocurrency in the town? economics of Cryptocurrency and friedrich a. hayek", Institute of Economic Research Hitotsubashi University, 2014.

[24] Mavrodiev, P, Garcia, D, Tessone, C. J, and Perony, N, "The digital traces of bubbles: feedback cycles between socio-economic signals in the bitcoin economy", ETH Risk Center, 2014.

[25] Sneppen, K, and Bornholdt, S, "Do bitcoins make the world go round? on the dynamics of competing crypto-currencies", 2014.

[26] Vivian, W and Vandey, P, "The Value of Bitcoin in Enhancing the Efficiency of an Investor's Portfolio", Journal of Financial Planning, September 2014.

[27] William, S. F, "The Sharpe ratio" The Journal of Portfolio Management, 1994.

[28] Yermack, D. "Is Bitcoin a Real Currency"? NYU Stern School of Business, 2013. 